\title{
Babel sikuri: circulación y dinamismo de estilos musicales al interior de una comunidad transnacional de resurgentistas de la música andina
}

\author{
Sikuri Babel: transference and dynamism of musical styles \\ within a transnational community of Andean music revivalists
}

\author{
por \\ Daniel Castelblanco \\ Wake Forest University, Estados Unidos \\ castelda@wfu.edu
}

\begin{abstract}
A partir de la emergencia del movimiento sikuri en la década de 1970, los músicos que participan en las escenas de varias ciudades latinoamericanas han interpretado estilos musicales indexales de diversos pueblos y regiones en los Andes centrales. Desde el sikumoreno de la ciudad de Puno hasta el jach'a sikuri de Ilabaya, ¿qué supone la elección de estos estilos?, ¿qué relación guarda con los flujos migratorios o las exigencias de la industria discográfica?, ¿qué revela acerca del movimiento sikuri en tanto plataforma por la que circulan formas alternativas de conocimiento? Más aún, ¿qué dice acerca de las distintas cohortes de músicos que lo conforman? Este artículo explora algunas de las consideraciones que los sikuris tienen en cuenta al escoger estilos musicales y repertorios. Argumenta que sus elecciones revelan preferencias estéticas, deseos de diferenciación, la voluntad de mantener lazos familiares, regionales o nacionales, e incluso sus propias agendas. Concluye que, pese la frecuencia con que se celebra el presunto carácter intercultural del movimiento sikuri, la formación cultural cosmopolita de quienes transmiten estas prácticas musicales y conocimientos de origen indígena demuestra lo contrario.
\end{abstract}

Palabras clave: Ilabaya, jach'a lakitas, representaciones de indigenidad andina, resurgimiento musical, transferencia cultural, transnacionalismo

Ever since the emergence of the sikuri movement in the 1970's the musicians who participate in most of its Latin American scenes have performed on a variety of indigenous musical styles indexical of different towns and regions in the Central Andes. From Puno city's sikumoreno to jach'a sikuri from Ilabaya, what does the preference for these styles mean? What kind of relationship does it keep with the migratory flows or the demands of the recording industry? What does it reveal about the sikuri movement as a platform through which alternative forms of knowledge are transferred? Moreover, what does it say about the different cohorts of musicians that make it up? This paper explores some of the considerations that the sikuris take into account when choosing their musical styles and repertoires. It argues that the sikuris' choices reveal their aesthetic preferences, their search for identity, their will to maintain family, regional or national ties, and even their own agendas. It concludes that, despite the frequency with which the sikuri movement is celebrated as a privileged site for intercultural exchange, the shared cosmopolitan cultural formation of those individuals involved in the transmission of these musical practices and other indigenous knowledges demonstrates quite the opposite.

Keywords: cultural transference, Ilabaya, jach'a lakitas, music revival, representations of Andean indigeneity, transnationalism. 


\section{BABEL SIKURI}

El Mathapi Apthapi Tinku es uno de los eventos más anhelados en el movimiento sikuri a nivel internacional. Durante mi última visita a Buenos Aires participé en su decimoquinta versión, en la que intervino medio centenar de agrupaciones con una variedad de instrumentos, estilos musicales y melodías indexales de diversas regiones de los Andes argentinos, bolivianos, chilenos y peruanos ${ }^{1}$.

Además de tarkas, quenas, pinkillos y otros instrumentos de viento, los ensambles que participaron ese año tocaron estilos regionales de flautas de cañas amarradas como kantus de la región de Charazani (departamento de La Paz, Bolivia), jach'a sikuri de la provincia Camacho (Depto. de La Paz, Bolivia), sikumoreno de la ciudad de Puno (Depto. de Puno, Perú), sikuri de Conima, Moho y Huancané (Depto. de Puno, Perú), sikuriada de Tilcara (provincia de Jujuy, Argentina), lakitas del norte de Chile (Región de Arica y Parinacota) y, significativamente, jach'a lakitas de Ilabaya (Depto. de La Paz, Bolivia) (Figura 1).

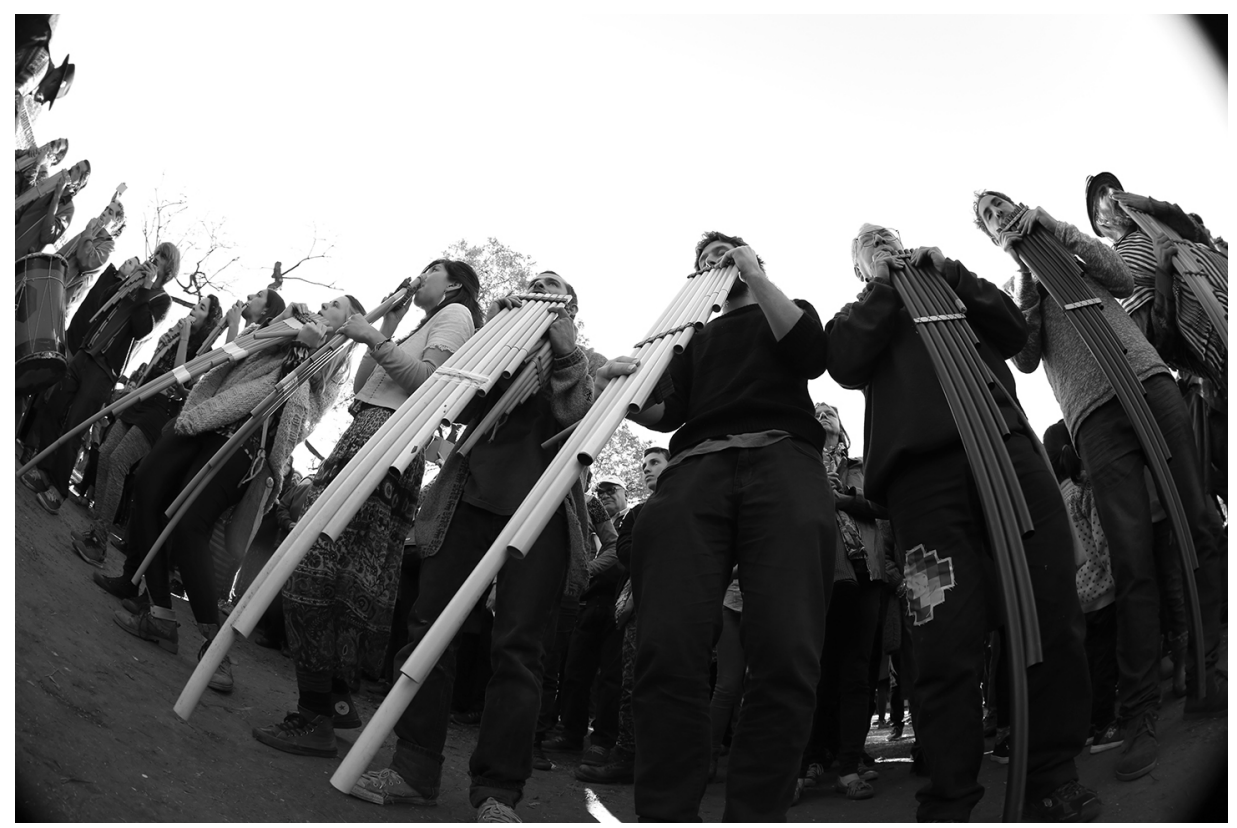

Figura 1: Conjunto ad hoc interpretando su propia versión de jach'a lakitas durante la decimotercera edición del Mathapi en la ciudad de Buenos Aires. Agosto de 2017. Foto cortesía de Eduardo Sarapura.

1 Agradezco a todos los músicos que contribuyeron a este trabajo haciendo memoria y compartiendo conmigo sus experiencias. En especial agradezco a Emiliano "Pino" Meincke, Erick Viscarra, Felice Clemente, Gilbert Arévalo, José Salgado, Marcel Didier, Raffaele Clemente, Rolando Pérez, Rubén Barreto y Víctor Colodro. Asumo la responsabilidad por cualquier desacierto u omisión. 
Sin lugar a duda, la convergencia de sonidos indexales de regiones tan diversas sería inimaginable en cualquier otro contexto. Por eso, impresionado durante su visita de 2013, el músico peruano José Falcón -una figura destacada en la escena sikuri limeña-, apellidó al Mathapi "la Babel de los sikuris". El célebre mote que Falcón dio al festival es el punto de partida para la discusión que propongo.

Aludiendo a la mítica torre babilónica donde habría surgido la variedad lingüística mundial, Falcón estableció un paralelo entre los estilos musicales sikuri y los lenguajes verbales. Esta es una comparación habitual entre los sikuris, muchos de quienes han conceptualizado su comprensión de la variedad estilística en términos análogos². A lo largo de la última década, numerosos conjuntos han experimentado con instrumentos y estilos musicales cada vez más "exóticos" (en el sentido de poco conocidos), incluyendo ayarachis de Paratía (departamento de Puno, Perú), chiriguanos de Huancané (Depto. de Puno, Perú), jula jula de Macha (Depto. de Potosí, Bolivia), sikuras de Isluga (Región de Tarapacá, Chile), sin mencionar estilos regionales interpretados en ensambles instrumentales distintos a los de flautas de cañas amarradas (Figura 2) ${ }^{3}$.

Partiendo de mi propia experiencia como participante e investigador del movimiento sikuri, en este artículo exploro el proceso por el que numerosos músicos cosmopolitas en grandes capitales latinoamericanas transfieren ciertos conocimientos de los indígenas aymara y quechua de los Andes centrales hasta sus respectivas ciudades. Argumento que la elección de instrumentos, estilos musicales y repertorios que los sikuris interpretan no es producto de la casualidad, sino la consecuencia de eventos puntuales en los que han influido agentes específicos y factores materiales concretos.

Empezaré por establecer una distinción entre las dos cohortes de músicos que componen el movimiento sikuri, para luego enfocarme en la conformada por entusiastas cosmopolitas en grandes ciudades latinoamericanas. A continuación describiré una tendencia común en el origen de distintas escenas sikuri, y explicaré ciertas peculiaridades con relación al tipo de fuentes de donde extraen su repertorio de melodías y estilos musicales.

2 Como indica el musicólogo Fabian Holt, resulta más difícil establecer teorías útiles acerca del género en la música que en la literatura o en la pintura debido a la naturaleza no referencial del sonido. Es decir que la música, incluso cuando está acompañada de palabras, carece de la precisión de las representaciones icónicas o indexales, por lo que los significados que se asocian a ella suelen ser altamente contingentes (Holt 2007: 5). No obstante, los sikuris han elaborado sus propias teorizaciones acerca de los elementos que dan forma a diversos estilos musicales. Entre las características sonoras que distinguen la interpretación musical sikuri en determinado distrito, pueblo, comunidad, ayllu, parcialidad o agrupación musical, los sikuris a menudo señalan la instrumentación (número ideal de intérpretes, tipo de instrumentos, afinación, percusión), secuencias sonoras (estructuras, tempo, ritmos, tipos de introducción, fugas y finali) y técnicas de interpretación (ataque, articulación, volumen), entre otras. Es importante señalar que además de los parámetros descritos, muchos también consideran ciertos elementos externos a la estética musical stricto sensu como parte de un determinado estilo. Los pasos de danza, las coreografías y la vestimenta característica que lucen sus intérpretes, e incluso las instancias sociales en que son tradicionalmente interpretadas constituyen, para muchos, parte integral de un estilo (Acevedo 2003: 21-27; Sánchez 2013: 362-368; Valencia 1983: 30).

3 Existe un puñado de agrupaciones que de manera consciente ha decidido crear sus propios estilos sikuri. De esta forma no solo consiguen sobresalir en sus respectivas escenas, sino que en cierto modo resuelven o sortean algunas de las paradojas que involucra replicar estilos musicales indexales de grupos étnicos o localidades distintas a la propia. Ese es el caso del estilo "San Marcos", del conjunto universitario Zampoñas de San Marcos (fundado en Lima en 1977), y del "sikuri Isleño", de la Banda de sikuris Churay churay (fundado en Tigre, provincia de Buenos Aires, Argentina en 2002). Para una discusión acerca de la relación entre estilo musical e identidad entre los sikuris de Lima ver Sánchez (2016). 
Entonces exploraré algunos de los antecedentes, hitos y protagonistas en la reciente popularización del estilo mejor conocido como "jach'a lakitas" -que en años recientes ha despertado el interés general del movimiento. A manera de conclusión propondré una reflexión acerca del carácter intercultural del movimiento sikuri.

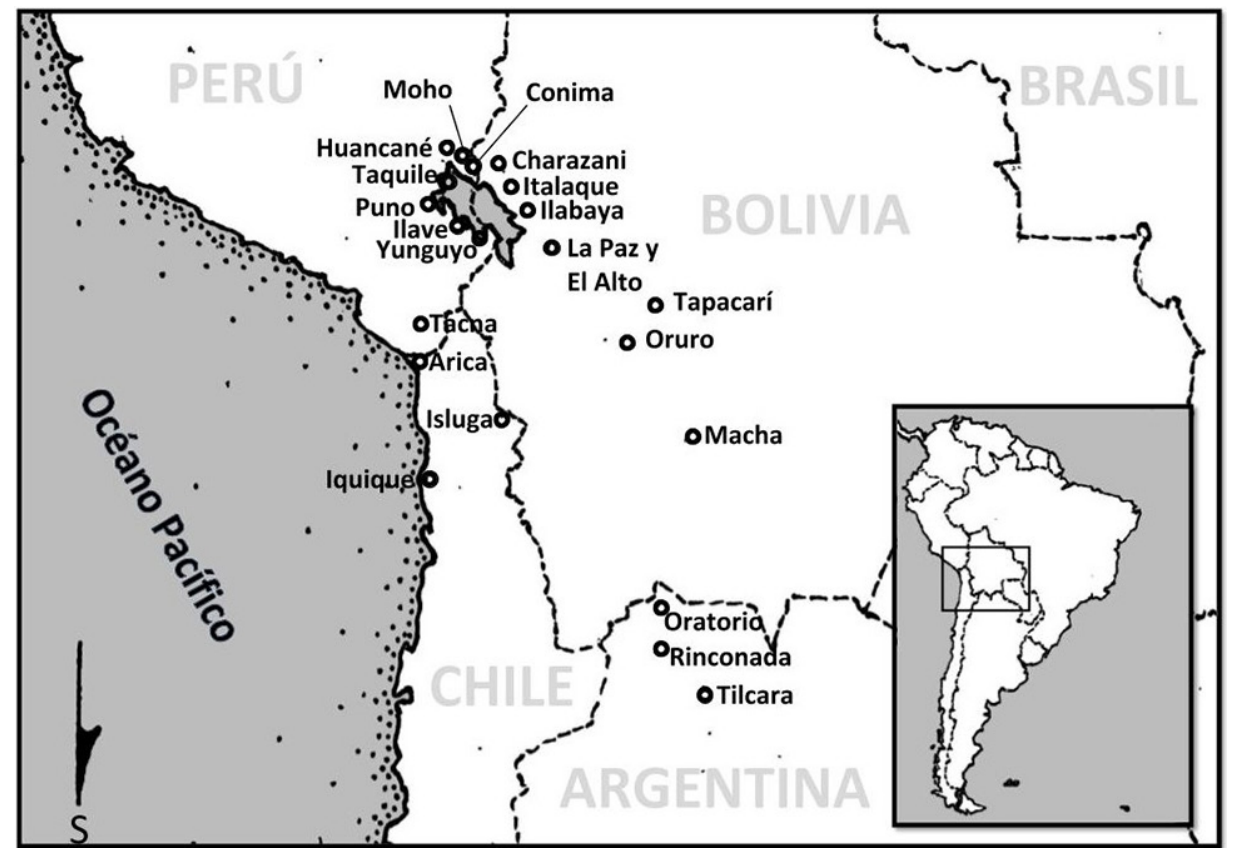

Figura 2: Focos de producción de algunos de los estilos musicales que la cohorte de sikuris "resurgentistas" interpreta. Fuente: Elaboración propia.

\section{EL MOVIMIENTO SIKURI: DOS COHORTES}

A partir de la década de 1970 ciudades como Lima, La Paz, Buenos Aires, Santiago y Bogotá han atestiguado el surgimiento y desarrollo de sus propias escenas musicales sikuri ${ }^{4}$. La progresiva articulación de dichas escenas y sus participantes mediante conexiones concretas, abstractas y virtuales ha favorecido la emergencia de un movimiento de relativa coherencia. Las conexiones concretas incluyen carreteras y rutas aéreas, mientras que las virtuales se basan en redes digitales como YouTube, Facebook y WhatsApp, que permiten intercambios de diversas clases entre sus participantes. Ambos tipos de conexión se intersecan y hacen posible el flujo multidireccional de personas, instrumentos musicales y sonidos y, a su vez, propician el establecimiento de conexiones abstractas en cuyo núcleo se halla la adopción

4 Entiendo las escenas musicales como instancias de interacción social de diversa índole que gravitan en torno a las diferentes prácticas musicales que en ellas coexisten, y en donde confluyen participantes con distintas trayectorias, identidades y estilos de vida que asumen varios roles y grados de implicación mientras comparten gustos musicales y se distinguen de otros (Peterson y Bennett 2004; Mendívil y Spencer 2016; Pedro, Piquer y Del Val 2018). 
general de valores solidarios, estéticas participativas, prácticas colaborativas e ideas de carácter gregario que unen a participantes individuales y sus respectivas escenas a nivel ideológico, otorgando al movimiento sikuri su identidad particular ${ }^{5}$.

En dichas escenas confluyen al menos dos grandes cohortes de músicos que interpretan una variedad de ensambles instrumentales y estilos musicales indexales de diversos pueblos y regiones andinas ${ }^{6}$. Por una parte, están aquellos que crecieron en contextos culturales donde este tipo de música responde a un traspaso generacional ininterrumpido, con frecuencia en poblados y aldeas en los Andes. Esta cohorte de músicos suele interpretar los estilos emblemáticos de sus respectivas regiones de origen, a menudo por medio de filiales o subsidiarias de los conjuntos locales. De manera significativa, estas personas suelen ser percibidas por los miembros de la segunda cohorte como maestros legítimos de quienes aprender la música. Siguiendo a Thomas Turino (2018: 21-22), denominaré a estos músicos como "hechos en casa" (homegrown).

La otra cohorte está conformada por entusiastas cosmopolitas quienes, pese a no haber crecido en contextos familiares, comunitarios o regionales en los que este tipo de música fuera traspasada de modo generacional, la adoptan e integran a sus propios entornos. Quienes están afiliados a esta cohorte tienden a asumir la misión de restaurar o preservar dichas tradiciones musicales debido a que se encuentran (o a que imaginan que se encuentran) en peligro de desaparecer. Del mismo modo, tienden a asumir dichas tradiciones como propias en virtud del legado histórico y los valores asociados que conllevan o que les atribuyen. Por último, suelen percibir su actividad como una alternativa a la alienación, inequidad y degradación moral promovida por la cultura dominante (Livingston 2014: 61). Debido a estas actitudes, Turino sugiere entender las actividades de esta cohorte de músicos como "resurgentistas" (revivalist) (Turino 2018: 21-22).

Mi artículo se enfoca en esta cohorte y en las fuentes a las que sus miembros acuden para acceder a los conocimientos y la música de los indígenas andinos en las grandes ciudades que habitan 7 .

5 Resulta imposible establecer una definición incontrovertible del movimiento sikuri debido a la enorme variedad de motivaciones, orientaciones ideológicas, niveles de compromiso y de experiencia que existe entre sus participantes. Al margen de estas distinciones, es importante resaltar que este circuito multidireccional está articulado mediante un conjunto consistente de prácticas musicales que potencialmente promueve la interacción y el flujo de personas e ideas, no solo entre ensambles y escenas por medio de fronteras nacionales, sino también entre individuos y culturas. Volveré acerca de este aspecto más adelante.

${ }^{6}$ Los participantes de cada escena sikuri caracterizan aquello que les distingue entre sí usando sus propias nomenclaturas. De modo semejante, diversas investigaciones proponen una variedad de categorías para clasificar a los participantes de cada escena de acuerdo con criterios que a menudo se enfocan en su origen nacional y regional, así como en su adscripción étnica (Acevedo 2003: 28-33; Podhajcer 2015: 57; Sánchez 2013: 151-180, 329-372; Vega 2016: 1069-1072, etc.). Ante las dificultades que conlleva el establecimiento de denominaciones estáticas basadas en las identidades étnicas o nacionales de los individuos, y teniendo en cuenta que este tipo de afiliaciones no garantiza en modo alguno el conocimiento o destreza musical de las personas, propongo acoger las categorías descritas a continuación (Castelblanco 2018; 2019: 111 n.12).

7 Estas categorías analíticas fueron originalmente formuladas por Turino para describir las escenas norteamericanas de música y danza old-time-que orbitan en torno a ensambles participativos de cordófonos acústicos guiados a menudo por violines en compañía de guitarras, banjos y mandolinas. Para efectos del presente estudio, considero pertinente conceptualizar la participación de los individuos que conforman las escenas resurgentistas sikuri mediante categorías análogas, debido a que hacen énfasis en los paradigmas estéticos y las comprensiones acerca de la música que dan forma a su actividad musical, y no en aspectos extramusicales contingentes o subsidiarios como sus filiaciones étnicas, 


\section{ESTILOS MUSICALES: DE LO GENERAL A LO PARTICULAR}

Debido a que cada una de las escenas que conforman el movimiento sikuri tiene características únicas, no es posible conceptualizar en modo general la trayectoria de las preferencias y significados que los sikuris han atribuido a cada estilo musical en el transcurso del tiempo. Factores particulares de cada escena como su composición demográfica, la presencia o ausencia de músicos "hechos en casa", la orientación ideológica y estética de sus figuras líderes, o el acceso a fuentes documentales las condicionan y modelan. No obstante, la etapa inicial de diversas escenas sikuri guarda ciertas correspondencias, que exploro a continuación (ver Castelblanco 2019: 107-113).

Durante su periodo germinal, muchos ensambles "resurgentistas" usaron una misma consorte de instrumentos para interpretar un repertorio ecléctico de melodías indexales de diversas regiones. Como resultado, su música fue algo así como una amalgama sonora en la que estaban ausentes aquellas marcas estilísticas con que los músicos de diversas regiones andinas, e incluso de una misma localidad, suelen diferenciarse (Sánchez 2013: 195; Turino 1993: 145$)^{8}$.

Durante la década de 1980 los residentes puneños en Lima interpretaron los estilos musicales de sus respectivas regiones de origen, mientras que los primeros conjuntos de la cohorte "resurgentista" aún no resolvían interpretar un estilo regional determinado. No solo ignoraban la existencia de diferencias estilísticas regionales, sino que tampoco tenían acceso a fuentes fonográficas o bibliográficas que les permitieran identificarlas. A causa de que sus integrantes provenían de Lima y otras regiones del país, su factor aglutinante no derivaba del deseo de expresar una identidad devocional, étnica o regional compartida, sino del gusto por hacer música juntos y la voluntad de manifestar su afinidad política con valores asociados a la izquierda (Falcón 2007: 112; Vidal 2012).

Los ensambles que inauguraron la escena sikuri de Buenos Aires en la década de 1970 estaban conformados principalmente por residentes de origen boliviano de diversa procedencia, quienes optaron por la expresión musical como forma de legitimar su presencia en la capital argentina. En un contexto adverso, marcado por la xenofobia y el racismo, los primeros ensambles privilegiaron como estrategia interpretar un repertorio común con el propósito de conformar grandes conjuntos ad hoc durante intervenciones públicas, y así atraer la atención y simpatía de la sociedad hegemónica (Barragán y Mardones 2018: 537; Gavazzo 2017: 50-51; Podhajcer 2015: 48; Vega 2016: 1068).

Colombia, debido a la inestabilidad política, al conflicto armado interno y a su precaria situación económica no ha atraído mucha migración internacional, salvo de países limítrofes como Ecuador y en años recientes Venezuela. La ausencia de músicos andinos "hechos en casa" ha conferido a la escena sikuri de Bogotá características particulares desde su origen en la década de 1980. Por ejemplo, los participantes han tomado como modelo y principal fuente de repertorio la discografía de agrupaciones de "música andina folclórica-popular"

regionales o nacionales. Turino advierte que distinguir entre ambas cohortes de músicos resulta cada vez más difícil debido a que muchos músicos "hechos en casa" asumen actitudes "resurgentistas", mientras que las nuevas generaciones de músicos que crecen en ambientes "resurgentistas" pueden ser también considerados como "hechos en casa". Este tipo de diferenciación, no obstante, sigue siendo relevante para algunas personas en lo relativo a la autenticidad (Turino 2018).

Debido a que no existe consenso respecto de la manera más apropiada de traducir al castellano el concepto music revival, opto aquí por emplear la forma "resurgimiento musical", y por llamar "resurgentistas" a sus agentes. Para una discusión más amplia acerca de la aplicación de ambas categorías al contexto del movimiento sikuri en Perú, ver Castelblanco 2018.

8 Esta es una tendencia que persiste, principalmente en las escenas sikuri de Bogotá y Buenos Aires. 
como Los Ruphay, Bolivia Manta, Grupo Aymara, Kollamarka, Awatiñas, etc ${ }^{9}$. Solo la visita ocasional de músicos allí reconocidos como "hechos en casa" ha ofrecido instancias a partir de las cuales los sikuris cuestionan los paradigmas estéticos que dan forma a sus interpretaciones musicales.

Es importante resaltar que la tendencia a tomar como modelo y fuente de repertorio las versiones de melodías indígenas producidas por agrupaciones de "música andina folclórica-popular" no es exclusiva de la escena bogotana, sino que de hecho es ubicua en el movimiento sikuri. Volveré a este asunto más adelante.

Por lo pronto basta indicar que, tras la etapa inicial que acabo de describir, ciertos conjuntos en cada escena iniciaron sus propios procesos para encontrar fuentes cada vez más originales, comparadas con las versiones cosmopolitas que inicialmente despertaron su interés. En muchos casos, este refinamiento desembocó en la elección del estilo musical de una región o localidad específica.

\section{FACTORES QUE DETERMINAN LA ELECCIÓN DE ESTILOS MUSICALES}

Ante la avasalladora heterogeneidad musical que caracteriza los Andes, y donde comunidades vecinas a menudo interpretan instrumentos, melodías y danzas completamente distintas, ¿qué motivaciones llevan a un conjunto de sikuris a escoger interpretar un estilo musical específico?

La elección de estilos musicales a menudo está emparentada con la aspiración de hacerlos visibles ante una sociedad dominante que los ha ocultado o que les ha sido históricamente indiferente (una misión que muchos sikuris describen como de "rescate"). Esta preocupación altruista define a la cohorte "resurgentista", y está en sincronía con otras motivaciones de orden ideológico y estético. Al mismo tiempo, coexiste con el interés o la curiosidad de los miembros de un conjunto en una región o localidad específica, con su búsqueda de diferenciación respecto de otros ensambles, y con su deseo de causar impacto al interior de una escena musical. A continuación examinaré algunas de estas motivaciones iluminándolas con ejemplos concretos.

\subsection{Motivaciones ideológicas}

La Asociación Juvenil Puno (AJP) es acaso el primer conjunto de sikuris "resurgentistas" fundado en Lima. Pese a que muchos de sus miembros eran oriundos de la ciudad de Puno, su interés en la interpretación de sikus solo emergió en Lima durante su etapa como estudiantes universitarios. Fue en la capital donde se inclinaron por la interpretación musical como actividad aglutinante, y donde resolvieron interpretar el estilo sikumoreno en virtud de sus asociaciones simbólicas con la clase obrera puneña-sus intérpretes por excelencia-.

En 1977 varios integrantes de la AJP viajaron desde Lima a la ciudad de Puno para articularse a distintos ensambles locales de sikumorenos durante la fiesta de la Virgen de la Candelaria. Concluida la fiesta, algunos se desplazaron hasta el pueblo de Conima para participar en los carnavales y conocer a los ya famosos músicos de Qhantati Ururi.

9 Siguiendo a Fernando Ríos (2008) en lo sucesivo empleo el término "música andina folclóricapopular" (Andean folkloric-popular music) para designar las adaptaciones de ciertas prácticas musicales participativas de los indígenas de los Andes a las convenciones estéticas cosmopolitas para su eventual mercantilización. El "conjunto andino" es el ensamble instrumental icónico de este estilo musical e incluye quena, charango, guitarra y bombo. 
Desde su fundación en Lima en 1970, la AJP había establecido por misión apoyar a la población indígena oprimida y rechazar el imperialismo cultural extranjero. Pero en Conima comprendieron que las connotaciones mestizas, urbanas y obreras que caracterizan el sikumoreno eran en cierto modo incompatibles con su agenda. Por el contrario, el impacto que les produjo Qhantati Ururi y la experiencia en Conima fue tal que, al retornar a Lima, abandonaron el sikumoreno y en su lugar adoptaron el estilo musical de Qhantati Ururi.

A pesar de su entusiasmo por interpretar este nuevo estilo musical, parte de los integrantes de la agrupación manifestó su preferencia por el sikumoreno aduciendo que tenía un ritmo "más alegre". Aun así, la AJP eligió el estilo sikuri de Qhantati Ururi, privilegiando la orientación ideológica del ensamble sobre las preferencias estéticas de sus integrantes. En breve, la AJP decidió que el estilo musical de Qhantati Ururi era más apropiado que el sikumoreno para demostrar su solidaridad con los pueblos indígenas oprimidos. Más aún, decidió que este estilo musical era más conveniente que el sikumoreno para que sus miembros se identificaran con su herencia étnica y se sintieran históricamente arraigados (Sánchez 2013: 195-197; Turino 1993: 149-151).

\subsection{Factores materiales}

Especialmente en el inicio del movimiento sikuri, cuando la posibilidad de acceder a fuentes discográficas y bibliográficas era menor, y cuando resultaba más difícil y costoso viajar a las fiestas en poblados andinos, la opción de elegir interpretar el estilo musical de una localidad determinada era casi una quimera. Así lo ejemplifica el caso del influyente Conjunto de Zampoñas de San Marcos, de Lima.

Durante sus inicios a finales de la década de 1970, estos jóvenes universitarios tocaban un estilo indeterminado que podía ser vagamente descrito como sikumoreno. A principios de la década siguiente, sin embargo, algunos de sus miembros consiguieron reunir tres discos comerciales de vinilo grabados por conjuntos del distrito puneño de Ilave (provincia de El Collao). Ante la dificultad de acceder a otro cuerpo consistente de fuentes fonográficas que les permitiera identificar y conceptualizar los elementos característicos de algún otro estilo, acogieron la proposición de José Salgado y se dedicaron a la interpretación exclusiva del ensamble instrumental y el estilo musical de dicha localidad (Acevedo 2003: 46, 54-55; Sánchez 2013: 360; Tarrillo 1998: 20; Vidal 2012).

\section{5. “ESTIRANDO” EL OÍDO}

Como mencioné en páginas anteriores, una característica fundamental de la cohorte "resurgentista" del movimiento sikuri consiste en su voluntad de hacer visibles ciertas prácticas y conocimientos de los indígenas de los Andes. Esta aspiración se extiende a aquellos estilos musicales que han permanecido ocultos o a los que la tendencia dominante dentro del movimiento ha sido indiferente (Acevedo 2003: 56). A lo largo de la última década, numerosos conjuntos de sikuris han experimentado con instrumentos y estilos musicales cada vez más "exóticos" (en el sentido de poco conocidos), incluyendo ayarachis de Paratía (departamento de Puno, Perú), chiriguanos de Huancané (Depto. de Puno, Perú), jula jula de Macha (Depto. de Potosí, Bolivia), suri sikuris de Venta y media (Depto. de Oruro, Bolivia) y sikuras de Isluga (Región de Tarapacá, Chile), entre otros.

En vista de que estos estilos musicales plantean un mayor desafío a los paradigmas estéticos dominantes, su apreciación a menudo demanda estilos de escucha más intelectualizados. Dentro de cada escena, es habitual que los primeros ensambles en enfrentar 
dichos desafíos sean aquellos con miembros regulares que privilegian la interpretación técnica de la música por encima de su dimensión participativa, y que tienen estilos de apreciación más analíticos.

Con frecuencia son estos ensambles los que introducen y "hacen accesibles" los nuevos estilos musicales al interior de las escenas y del movimiento sikuri en general. Cuando digo que los "hacen accesibles", no solo me refiero a que presentan dichos estilos como una posible veta de exploración musical, sino también a que los procesan estética y conceptualmente (en mayor o menor grado, dependiendo de la meticulosidad del ensamble), de modo que resultan atractivos e inteligibles a audiencias mayores. Gracias a este proceso, eventualmente ciertos estilos llegan a ser interpretados por otros conjuntos, con lo que pueden popularizarse ${ }^{10}$.

La dinamización de las preferencias estéticas entre la cohorte "resurgentista" del movimiento sikuri sigue una trayectoria que, si bien es subjetiva, suele ceñirse a un patrón. Turino la describe del siguiente modo: es habitual que los cosmopolitas se sientan atraídos hacia sonidos que perciben como "nuevos" o "exóticos". Sin embargo, ya que los gustos musicales de los individuos tienen la forma de sus experiencias previas, el nuevo estilo musical debe asemejarse en cierta forma a la música con que estos están familiarizados, al menos como punto de partida, para que les resulte atractivo (Turino 2008: 137). A medida que los oyentes se acostumbran al nuevo sonido, su gusto musical se expande. Turino llama a este proceso "estiramiento del oído" ( listeners "stretch their ears"), y argumenta que prepara gradualmente a las personas para sonidos nuevos y cada vez más distintivos.

Sostengo que un proceso semejante ha hecho posible el reciente éxito del estilo musical conocido como jach'a lakitas (departamento de La Paz) al interior del movimiento sikuri ${ }^{11}$.

10 Las transformaciones estéticas incluyen el uso de instrumentos de afinación regular en lugar de instrumentos de entonación flexible, la preferencia por el timbre claro sobre el denso, la inclinación por la homofonía a cambio de la monofonía y la apariencia estilizada como sustituto del carácter "emplumado" o "desprolijo" que suele ser la norma en los contextos tradicionales de producción musical. Aunque en este listado contrasto algunas de las transformaciones estéticas más recurrentes con ciertas características musicales presentes en diversas zonas de los Andes centrales, reconozco que no es posible establecer un compendio unificado de las convenciones estéticas que dan forma a la producción musical en una región geocultural tan diversa como los Andes, donde múltiples ideales sonoros coexisten distribuidos de manera irregular.

11 Esta constelación de estilos musicales, ampliamente definida, se conoce de forma alternativa como "jach'a lakitas" y "jach'a sikuri” y es tradicionalmente interpretada por campesinos indígenas en el departamento de La Paz (provincias de Camacho, Larecaja y Omasuyos). Es importante advertir que no existe algo así como un breviario unívoco de formas y convenciones estéticas que aglutinen las expresiones musicales que los campesinos indígenas de distintas regiones andinas llaman "jach'a lakitas" o "jach’a sikuri”. Es más, conjuntos de comunidades colindantes suelen valorar su respectivo sonido como una marca distintiva. No solo interpretan un repertorio propio, sino que incluso expresan su diferencia mediante el uso de instrumentos afinados en tonalidades distintas. Acaso la característica más relevante que estas expresiones musicales comparten sea el uso de sikus o lakitas de gran tamaño. De ahí que su denominación incluya el adjetivo "jach'a" (aymara: "grande"). Si me refiero a este estilo musical en singular, pese a su diversidad interna, lo hago porque esta es la forma en que los sikuris lo conceptualizan.

Al mismo tiempo, es importante señalar que jach'a lakitas hace parte de la extensa familia de consortes instrumentales conocida como "lakitas", cuyas características varían sustancialmente en las regiones de los Andes centrales donde son interpretadas. Estas consortes constan de parejas de flautas divididas entre 3 y 4 registros tonales con acompañamiento de bombos o wankaras. De mayor a menor tamaño suelen incluir taykas (también llamadas jach'as, sanjas o jatun sanjas), maltas (también malas) y ch'ulis (también ch'ilis o ch'iris). Son interpretadas por músicos indígenas en Bolivia en los departamentos de La Paz (provincias Aroma, Ingavi, Larecaja, Loayza, Los Andes, Omasuyos, 


\section{DESDE UN PEQUEÑO CANTÓN}

Históricamente, los estilos musicales más populares en la escena sikuri de Lima han sido los de Conima, Moho, Ilave y Yunguyo. Fuera de Perú, los estilos sikuri más populares son, sin lugar a duda, los de la región de Charazani y la provincia Camacho. En años recientes, sin embargo, numerosos conjuntos de sikuris en todas las escenas han empezado a experimentar con los instrumentos de gran tamaño que caracterizan el estilo conocido como jach'a lakitas, y que relacionan con mayor frecuencia al cantón de Ilabaya (provincia de Larecaja, departamento de La Paz, Bolivia). A la fecha he identificado veinticinco agrupaciones asociadas a la cohorte "resurgentista" que interpretan estos instrumentos y dicho estilo musical con diversos resultados, no solo en grandes capitales latinoamericanas, sino en ciudades como Córdoba, Mendoza, La Serena y Valparaíso. Entonces, ¿a qué se debe la popularización del estilo y su asociación a este pequeño cantón? ¿Por qué se produjo recién al iniciar el nuevo milenio? (ver Figura 3) ${ }^{12}$.

Pacajes, etc.) y Cochabamba (provincias Capinota, Mizque, etc.). En Chile en las regiones de Arica y Parinacota (provincias Arica y Parinacota) y Tarapacá (provincias Iquique y Tamarugal). En Perú en el departamento de Puno (provincia Yunguyo) (ver Baumann 1982; González Bravo 1949; Mora 2012, etc.).

12 Entre estos conjuntos musicales se encuentran Agrupación Kollasuyu (Santiago), Aruskipasiñani (Santiago), Comunidad sagrada coca (La Paz), Comunidad sikuris del arcoiris (Buenos Aires), Comunidad surimanta ayllu (Lima), Espíritu sikuri (Lima), Jach'a golondrinas (Mendoza), Jacha marka (Buenos Aires), Jach'a q'ota sikuris (Valparaíso), Tropa Los sikuris (Bogotá) y Ukhu pacha (San Francisco). Incluyo estas agrupaciones debido a su propia percepción acerca de la música que interpretan (expresada en los títulos o descripciones que asignan a dichas melodías en sus presentaciones públicas y discos), y no necesariamente porque todas ellas incorporen, stricto sensu, las idiosincrasias estéticas que caracterizan a los conjuntos de jach'a lakitas de alguna comunidad indígena específica. En efecto, fuera de reproducir de forma más o menos esquemática el repertorio canónico de motivos melódicos de este estilo musical, algunas de estas agrupaciones soslayan precisamente aquellas cualidades sonoras que lo distinguen, como el ritmo de compás asimétrico, la articulación staccato y la presencia de sonidos armónicos. Algunas de estas agrupaciones emplean consortes de instrumentos extemporáneos, ya sea por su tonalidad, configuración instrumental o materiales. Aquellas que cuentan con consortes fabricadas especialmente para interpretar este estilo musical a menudo privilegian el uso de taykas (el registro tonal de mayor tamaño), comprometiendo con ello el equilibrio del ensamble. Incluso hay agrupaciones que omiten los demás registros, emulando la configuración instrumental de las denominadas "toyadas" que popularizaron conjuntos andinos a partir de la década de 1970. Lo que es más, muchas truecan la función sonora de las taykas pues, siguiendo la lógica de que los instrumentos grandes deben producir sonidos graves, desestiman su potencial para producir los finos sonidos armónicos que los jach'a lakitas suelen buscar en ellos. Debo advertir que si enfatizo las divergencias que existen entre los atributos estéticos de los jach'a lakitas y los que caracterizan las versiones de algunos conjuntos "resurgentistas" de sikuris, no lo hago con fines valorativos, sino con el propósito de establecer qué tipo de transformaciones ocurren en el proceso de transmisión de estas prácticas musicales. 


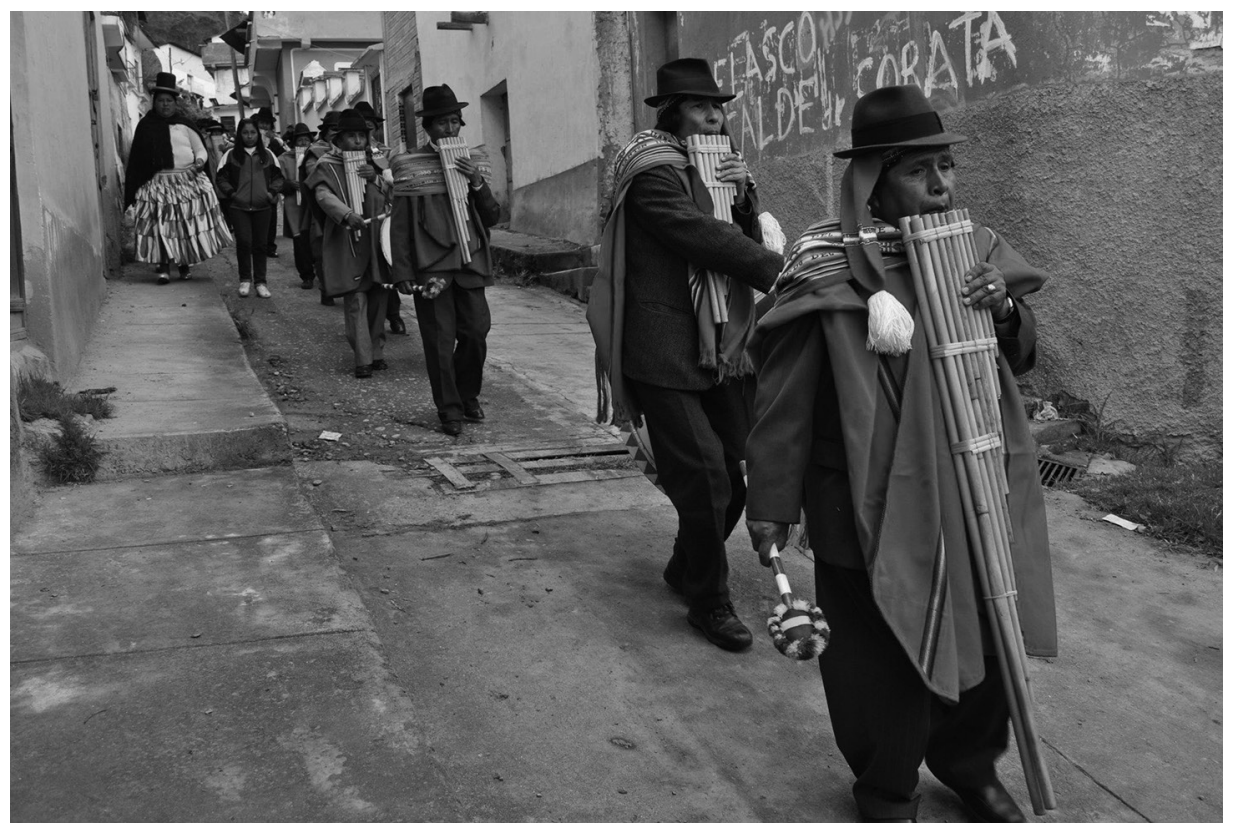

Figura 3: Músicos de la comunidad Huancané durante la fiesta patronal en honor a Jesús del Dulce Nombre en Ilabaya (departamento de La Paz, Bolivia). Enero de 2012. Foto cortesía de Eugenia Sik.

Mientras que es posible atribuir la vasta diseminación del kantus de Charazani o el denominado sikuri "de Italaque" a individuos que asumieron un papel activo como sus promotores durante la primera mitad del siglo XX (e.g., el folklorista Antonio González Bravo), así como a las políticas culturales de instituciones con agendas concretas (e.g., el gobierno del MNR en Bolivia), el caso de los jach'a lakitas requiere una aproximación distinta (Castelblanco 2017; Wahren 2016: 79-112) ${ }^{13}$.

13 Admito que denominar como "sikuri de Italaque" la constelación de variedades musicales que los campesinos aymara de la Provincia Camacho (Departamento de La Paz) interpretan con sikus, sin ofrecer una problematización de esta categoría, conlleva efectos adversos. Para empezar, el uso indiscriminado de esta denominación eclipsa el deseo de sus intérpretes de hacer de sus prácticas musicales un vehículo de expresión de su identidad étnica y su pertenencia geográfica. Por otro, inhibe la posibilidad de apreciar las ricas variedades estéticas a través de las que los ensambles comunitarios de la región se distinguen unos de otros. Como si fuera poco, el uso de esta categoría hace eco de las condiciones de esclavitud a la que los antiguos patrones residentes en el casco urbano de Italaque sometieron a los campesinos de la región. No solo oscurece el hecho de que -hasta hace muy poco-, no existían conjuntos de sikuris basados en Italaque, sino que soslaya la coerción que ejercían los hacendados para conseguir que los ensambles de músicos campesinos tocaran en la plaza de su pueblo en fechas señaladas. En años recientes, tanto los guías de algunos de estos ensambles, como ciertos intelectuales locales, han hecho explícita su voluntad de que se distinga la música que interpretan sus respectivos conjuntos mediante adjetivos que suelen evocar sus respectivos lugares de origen. En la contraportada de la más reciente producción videográfica del Conjunto autóctono Jachayiris, Jorge Juan Cachi, uno de sus guías subraya: "No queremos que nos conozcan ni tampoco queremos que nos digan los Sikuris de Italaque; porque nosotros no somos de Italaque; somos de Tajani, comunidad Purani 
Es posible que los políticos e intelectuales indigenistas que celebraron dichos estilos musicales percibieran las peculiaridades sonoras de los jach'a lakitas como incompatibles con sus preferencias estéticas y, por extensión, con su propósito de persuadir a la sociedad dominante del valor de las culturas indígenas como componente central de su proyecto de nación mestiza. Acaso por esto, los responsables de la popularización de este estilo musical no fueron políticos o intelectuales, sino músicos afiliados a los proyectos culturales de la Nueva Canción Latinoamericana ${ }^{14}$.

En respuesta al éxito nacional e internacional de la "música andina folclórica-popular" y la creciente inclinación de los músicos locales a estilizar ritmos y melodías de origen indígena para adaptarlos al ensamble multiinstrumental del "conjunto andino" (i.e., quena, charango, guitarra y bombo), entre los jóvenes de la ciudad de La Paz surgió a mediados de la década de 1970 una tendencia a replicar las músicas de los indígenas andinos interpretando consortes de instrumentos de viento (Céspedes 1984: 240-241).

Entre las décadas de 1980 y 1990 la música de tropa cobró en Bolivia mayor valor simbólico. Como advierte Michelle Bigenho (2002: 113), esta reacción se produjo en sincronía con lo que Xavier Albó denominó "El retorno del indio" (1991) -la respuesta de las organizaciones indígenas a la retórica campesinista y uniformadora impulsada desde la administración del Movimiento Nacionalista Revolucionario tras la Reforma Agraria de 1953, con la que se pretendió despojar de su componente étnico y cultural las luchas anticoloniales de los indígenas en Bolivia. El katarismo fue la expresión más acabada del rechazo de ciertos sectores indígenas aymara al proyecto uniformador de nación formulado por el gobierno revolucionario. Entre los elementos más protuberantes de la ideología étnica con que expresaron su identidad distinta, aymara, sobresalen su nombre y los héroes que reivindican, la wiphala, la revaloración de sus autoridades, vestimenta, lengua y-de manera significativa-, la música de tropa que difundieron de forma consistente por medio de las ondas radiales (Albó 1991: 312).

Hacia mediados de la década de 1970 en La Paz y otras ciudades bolivianas, un creciente número de jóvenes alineados con esta tendencia quiso retornar a las raíces de aquella música que ahora protagonizaba las portadas de los discos y animaba las peñas. Tanto en sus discos como en sus presentaciones públicas, dichos conjuntos fueron otorgando cada vez mayor protagonismo a sus propias interpretaciones de "música autóctona", que reunieron a menudo bajo el concepto de "estampas folclóricas". Las estampas consistían en un popurrí de melodías enlazadas en las que era posible apreciar una variedad de estilos

Kollacara (...) dolidos estamos, desde aquel día en que nuestros abuelos, padres y hermanos fueron sometidos por los patrones de Italaque, para que en cada Corpus Christi la población de Tajani al igual que otras comunidades lleven su conjunto de sikuris a la población de Italaque; que si no lo hacían eran humillados, castigados o esclavizados. La fiesta se convirtió en un encuentro grande de sikuris por muchos años; de ahí el nombre de Sikuris de Italaque” (sic). Una discusión análoga es aplicable a otros estilos musicales que suelen ser denominados mediante categorías genéricas, como "kantus de Charazani", "sikuri de Conima" o "jach'a lakitas de Ilabaya" -por nombrar solo algunos. Para efectos del presente artículo, designaré en modo general esta variedad de estilos regionales como "sikuri de la provincia Camacho". Cuando me refiero al "sikuri de Italaque" -entre comillas y en singular-busco reflejar el carácter homogéneo y simplificado con que esta constelación de variedades musicales suele ser percibida desde una perspectiva externa.

14 Los mismos intelectuales indigenistas que privilegiaron los kantus y el estilo sikuri icónico de la provincia Camacho estaban en conocimiento de la mayor fiesta de Ilabaya y, por extensión, es posible que supieran de la existencia de los jach'a lakitas locales (ver Bedregal y González 1956: 9). Sospecho que si no estuvieron entre sus preferidos no fue porque no los distinguieran, sino, acaso, debido a la incompatibilidad entre sus propias preferencias estéticas y ciertos aspectos como los sonidos armónicos que caracterizan este estilo musical. 
musicales y consortes instrumentales (e.g., sikus, tarkas, pinkillos, etc.). Especialmente durante escenificaciones en vivo, los músicos articulaban la interpretación musical con danzas, vestuarios y la denuncia de los problemas que enfrentaban las comunidades indígenas andinas (Céspedes 1984: 241). Gracias a la variedad de estilos, instrumentos, timbres, melodías, danzas y vestimentas que reunían, las estampas folclóricas cumplían con el propósito múltiple de impresionar, sensibilizar, educar y entretener a su audiencia.

Precursores de esta innovadora tendencia, ensambles como Los Ruphay y Grupo Aymara no tardaron en cosechar imitadores entre las clases populares urbanas en la ciudad de La Paz (Ríos 2005: 610). Una de las primeras agrupaciones de esta línea en publicar su propia versión de un jach'a lakita de Ilabaya fue Kollamarka (1984) -cofundada por Armando Portugal, natural del mismo pueblo-. Le sucedieron agrupaciones como Kollasuyu Nan Bolivia (1986) y Bolivia Manta (1989).

Pero los discos en que aparecieron publicadas estas melodías contenían mucho más que jach'a lakitas. Siguiendo el ideal de integración latinoamericana originalmente formulado por artistas vinculados a la Nueva Canción Latinoamericana, como Los Calchakis y Los Incas, la discografía de estas agrupaciones incluía una variedad de estilos musicales indexales de regiones andinas más allá de los límites nacionales de Bolivia (Céspedes 1984; Katz-Rosene 2015; Ríos 2008).

En respuesta a la macabra política exterior de Estados Unidos en Latinoamérica ${ }^{15}$, estos músicos reunieron instrumentos y músicas disímiles convencidos del poder de su obra para renovar la unidad que Sudamérica habría experimentado hacia el final del período precolombino, cuando los límites del Imperio Inca se expandieron más allá de las fronteras actuales de los países del área andina (Ríos 2008: 156). Además, estos artistas se proponían ofrecer una muestra de la diversidad de instrumentos y estilos musicales de los pueblos indígenas de los Andes. Por tanto, las melodías de jach'a lakitas que incluyeron en sus discos aparecieron imbricadas en un ecléctico entramado musical junto a kantus e "Italaques", además de melodías interpretadas con diversas consortes instrumentales como la del "conjunto andino" 16.

Pero un aspecto particular capturó la atención de sus audiencias europeas y latinoamericanas, ya en vivo durante la escenificación de "estampas folclóricas", como en las portadas y láminas interiores de sus discos: el gran tamaño de los instrumentos con que interpretaron sus versiones de jach'a lakitas.

15 Me refiero a la red clandestina conocida como Plan Cóndor, organizada y financiada por el gobierno de Estados Unidos durante la Guerra Fría para eliminar a quienes se opusieran a las políticas de la economía neoliberal, y erradicar los movimientos vinculados con el ideario comunista en Latinoamérica.

16 Es importante notar que, si la diversidad de consortes instrumentales y estilos regionales que estos ensambles ofrecía era consecuente con su actitud política a nivel discursivo, esta misma variedad tenía una finalidad práctica a nivel conceptual: la interpretación de un único estilo musical y, más aún, la repetición prolongada de un mismo motivo melódico como el que suele marcar el transcurso de las fiestas patronales en las aldeas de los Andes centrales, resultaría monótona desde la perspectiva de la audiencia que asistía a sus presentaciones artísticas en salas de teatro, o que compraba sus discos. En otras palabras, dicho eclecticismo hacía parte del repertorio de estrategias mediante las que estos artistas adaptaron la música de los campesinos indígenas a las disposiciones musicales dominantes y a la lógica del formato presentacional. 


\subsection{Un escollo: el toyo}

Inspirados en las dimensiones de las taykas -el registro tonal de mayor tamaño en esta consorte de flautas-, en la década de 1970 artistas asociados a la Nueva Canción Latinoamericana crearon instrumentos colosales que llamaron "toyos". Agrupaciones de música andina folclórica-popular como Los Ruphay (e.g., "Jach’a marka” (1981)) y Grupo Aymara (e.g., "Mi raza" (1973)) interpretaron estos instrumentos en consortes semejantes a las de las tradiciones indígenas, y así establecieron las bases del novedoso género que llegaría a conocerse como "toyada" (figura 4) ${ }^{17}$.

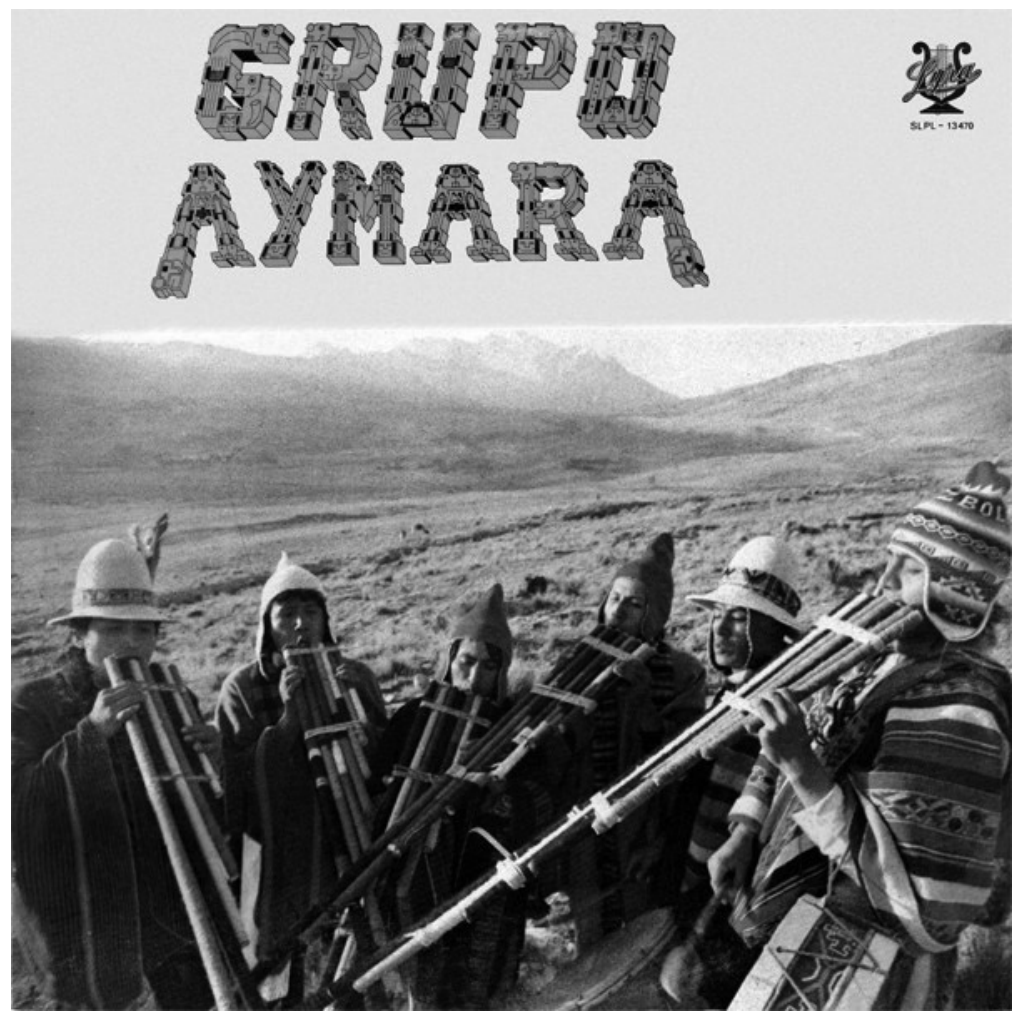

Figura 4: Portada de uno de los discos de Grupo Aymara (1982).

Fuente: Archivo personal del autor.

El tono grave y timbre opaco de los toyos, y en especial su impacto visual, fueron recibidos con tal entusiasmo por la audiencia de estas agrupaciones, que pronto pasaron a formar parte esencial de su repertorio. Sin embargo, la manera arbitraria en que muchos

17 El impulso por innovar con instrumentos de gran envergadura no se detuvo allí. Como advierte Michelle Bigenho (2012: 93), artistas japoneses aficionados a la música andina están construyendo instrumentos incluso más grandes que los toyos. 
de estos artistas identificaron sus composiciones para toyos en la contratapa de sus discos y en las notas internas que los acompañaban, indujo a un equívoco que trascendió. En efecto, algunos de los más influyentes conjuntos andinos usaron de forma alternativa denominaciones como "jach'a sikuris" y "jach'a lakitas" para identificar las "toyadas" de su invención. El equívoco fue especialmente persistente debido a que, en las notas internas que acompañaban muchos de esos discos, numerosos grupos incluyeron algo así como una declaración de propósito en la que señalaban como sus objetivos -palabras más, palabras menos-, "investigar, valorar, rescatar y difundir la música indígena de los Andes para enfrentar las fuerzas colonizadoras de la globalización" (ver Grupo Aymara 1995, etc.).

Esta narrativa dificultó a las audiencias neófitas establecer una distinción entre aquellos elementos que eran producto de la creatividad de los artistas, y los instrumentos, melodías y marcas estéticas de origen indígena. Al mismo tiempo, contribuyó a diseminar la asociación errónea entre jach'a lakitas y "toyadas" -expresiones musicales que no solo tienen características instrumentales y estéticas sustancialmente distintas, sino que se originan y responden a diferentes disposiciones musicales (la performance participativa y la presentación artística, respectivamente).

Como consecuencia, algunos conjuntos de sikuris asociados a la cohorte "resurgentista" emplean hoy las locuciones "jach'a lakitas" y "toyadas" de forma intercambiable como si se tratara de términos equivalentes. Es más, la calidad de los sonidos que producen con estos instrumentos a menudo guarda mayor semejanza con el timbre grave y opaco de los toyos, que con el timbre agudo y rico en armónicos que los músicos de comunidades como las que circundan el pueblo de Ilabaya suelen preferir.

Sin lugar a duda, los toyos y las "toyadas" alimentaron la fiebre por la música andina tanto en Latinoamérica como en Europa. Pero en el viejo continente, la confluencia de agrupaciones con diversas orientaciones, la oferta de la industria discográfica y una audiencia ávida de experiencias acústicas exóticas, favoreció las condiciones para el surgimiento de una agrupación cuya obra influiría de forma decisiva en la popularización de este estilo musical.

\subsection{Trencito de los Andes}

Fundada por los hermanos italianos Felice y Raffaele Clemente, Trencito de los Andes (1974-2006) ha desempeñado un papel crucial en el proceso de popularización del estilo musical jach'a lakitas al interior del movimiento sikuri. Por un lado, debido a que numerosos conjuntos de sikuris conformaron su repertorio de este estilo musical tomando como modelo algunas de las versiones facsimilares que esta agrupación produjo a base de melodías recopiladas por sus miembros en Bolivia como "Suma conjunto" (2002) o "Jacha Walata" (2003a). Acaso más importante, porque Trencito de los Andes propició la apreciación de este estilo musical por medio de originales composiciones en las que, más allá de replicar en modo literal ciertos motivos melódicos de jach'a lakitas, los puso a dialogar con diversas tradiciones musicales y ensambles instrumentales. "La parábola de Juvencito", una de las melodías que ha tenido el mayor éxito entre la cohorte de sikuris "resurgentistas", proporciona un buen ejemplo de ello.

"La parábola de Juvencito" está basada en un tono cuya primera versión grabada se remonta a la del conjunto de lakitas de Chua (provincia de Omasuyos, departamento de La Paz). En la década de 1980, integrantes de este conjunto campesino llevaron grabaciones de su música a los estudios de Radio San Gabriel, en la ciudad de La Paz, para que fueran emitidas. Con el tiempo estas mismas grabaciones pasaron a formar parte del archivo de la emisora. Hacia finales de la década de 1980, músicos de Trencito de los Andes visitaron esta sonoteca radial y tuvieron acceso a las cintas en que se encontraba grabado el conjunto de lakitas de Chua. De regreso en Italia grabaron sus propias versiones facsimilares de algunas 
de esas melodías, incluyendo una que entonces llamaron "Waycheñita", y las reunieron en un casete no comercial titulado Jaccha sikuris (1990).

Una década después, Trencito de los Andes reelaboró esa misma melodía dentro del disco Escarcha y sol (2000), obra que fue producto de la colaboración entre Trencito de los Andes, el charanguista histórico de Inti Illimani, Horacio Durán, y el poeta y narrador de cuentos Osvaldo Torres. Además, contó con la participación especial del Quinteto Cinquelyre y otros artistas invitados. Este disco hila ensambles instrumentales y estilos musicales de distintas regiones andinas por medio de varios cuentos originales que reflexionan acerca de la muerte, el amor, la creación musical y diversos aspectos de la vida en los Andes. En ellos, Osvaldo Torres emplea la primera persona para interpretar al campesino andino, a quien da voz en algunos de sus trabajos previos como Desde los Andes a la ciudad (1980). De este modo, los cuentos de Escarcha y Sol oscilan entre la crítica social de la narrativa indigenista y la persuasión afectiva del relato testimonial.

"La muerte de la Kusisiña Mamani" es la pieza que inaugura el disco y está compuesta por tres movimientos articulados mediante un relato que denuncia los abusos y la injusticia histórica que el sistema de haciendas ha impuesto a los campesinos indígenas en los Andes. El relato inicia cuando el narrador, que pastorea en la puna, escucha el golpe cardíaco de bombos y campanas que anuncian el asesinato de la mujer de su compadre Juvencio a manos del patrón. El narrador va entonces en busca del viudo. Lleva consigo hojas de coca, alcohol y una guitarra de palo para consolarle. "Juvencio: no hay sangre que la tierra olvide, jilata" -le conforta- "ya llegará el día en que paguen los que no han pagado", -advierte evocando el leitmotiv del pachakuti, la utopía andina por excelencia que vaticina la inversión de la realidad y, con ella, el advenimiento de la justicia-.

A nivel musical, "La muerte de la Kusisiña Mamani" articula ingeniosamente las voces de una guitarra y una orquesta de cámara, con una consorte de jach'a lakitas que irrumpe en el tercer y último movimiento de la pieza. Este inicia con el canto del protagonista, ahora en la voz de Felice Clemente, que conmina a su compadre a pasar la noche en su compañía. Los arreglos para guitarra dialogan con la melodía del canto, ya de forma disonante como consonante, hasta que se eclipsan detrás de un ensamble de jach'a lakitas que parece aproximarse tocando y cantando versos que emulan los de un manifiesto: "Somos los jach'a sikuris, wawita / Nosotros bailamos así, huaycheña / Con nuestros bombos de tacho, wawita / Oscilando avanzamos, huaycheña / Al son de estos tubos largos, wawita / Oscilando avanzamos, huaycheña / Como martillo en su clavo / Vamos derecho al corazón, wawita / Orgullosos y sencillos / El paisaje sacudimos, huaycheña".

Pese a su relativa brevedad dentro de la obra, el motivo melódico de "La parábola de Juvencito" causó tal impacto entre la cohorte de sikuris "resurgentistas", que hoy constituye parte esencial de su repertorio de jach'a lakitas. Más aún, de aquellos conjuntos que interpretan esta melodía, la mayoría también canta los versos compuestos por Felice Clemente. Este hecho es indicio de que los sikuris no solo fueron cautivados por la belleza del motivo melódico originalmente grabado por el conjunto campesino de lakitas de Chua. Su apreciación de este estaría condicionada por la poética de los versos, la narrativa emotiva de Osvaldo Torres y el encanto de los arreglos para orquesta de cámara y guitarra a cargo de Raffaele Clemente. En pocas palabras, la composición musical en la que esta melodía de jach'a lakitas se encuentra imbricada constituiría una forma de procesamiento musical que a la larga habría contribuido a su apreciación entre los sikuris.

Sospecho que un efecto semejante ocurrió con otras melodías originalmente compuestas por conjuntos de campesinos indígenas y reinterpretadas por Trencito de los Andes, como el tono original de los comunarios de Ch'eje (Ilabaya, provincia de Larecaja, departamento de La Paz) que aparece en Il puma e gli arconauti bajo el nombre "Suma conjunto" (2002). 


\subsection{Otras agrupaciones artísticas}

Tras revisar el catálogo discográfico producido por los conjuntos de música andina folclóricapopular más relevantes, he conseguido identificar treinta y cinco melodías, publicadas entre 1981 y 2004, que sus intérpretes identifican alternativamente como "jach'a sikuri" o "jach'a lakitas" -incluyendo las que aparecen en los discos de Kollamarka (1984), Bolivia Manta (1989), Grupo Aymara (1995) y Willkamayu (2004)-. Algunos de estos motivos melódicos -en especial los que pueden escucharse en la discografía de Kollamarka (1984, 1994 y 2002)-, fueron replicados con insistencia por otros conjuntos de música andina folclórica-popular.

Pero no sería hasta 2005 que un conjunto de sikuris destinara parte importante de su trabajo en el estudio de grabación a este estilo musical. Conformado por personas de distintas nacionalidades con base en la ciudad de Buenos Aires, Wayramanta produjo su primer disco bajo la dirección de Rubén Barreto. Este trabajo inaugural estuvo compuesto por catorce melodías interpretadas en los estilos indexales de diversas regiones andinas que, además de jach'a lakitas, incluyeron el sikuri icónico de la provincia Camacho (departamento de La Paz, Bolivia), sikumoreno de Ilave (provincia de El Collao, Depto. de Puno, Perú), y suri sikuri de la provincia Dalence (Depto. de Oruro, Bolivia). Desde su fundación en 1993, Wayramanta experimentó con estos y otros estilos sikuri. Pero fue en el transcurso de los primeros años del nuevo milenio que el influyente músico boliviano Víctor Colodro les sugirió iniciarse en el estudio de jach'a lakitas.

Colodro ha participado en diversas escenas de música andina tanto en Bolivia (donde integró agrupaciones como Kollamarka) como en Europa (donde hizo parte de Bolivia Manta y Trencito de los Andes, entre otras). En la actualidad dirige el Centro Willkamayu en la ciudad de La Paz, en cuya guía ha producido tres discos compactos. La relación de Colodro con este estilo musical se remonta a los inicios de la década de 1990, cuando visitó el cantón de Ilabaya por primera vez. Cautivado por las músicas y danzas regionales, y en especial por la amistad que le ofrecieron las personas que allí conoció, regresó al cantón en múltiples ocasiones, involucrándose en la vida social de Huancané -una de las comunidades circundantes-.

A principios del siglo XXI Colodro pasó numerosas temporadas en la ciudad de Buenos Aires, donde asumió la dirección musical de Wayramanta en modo intermitente. Fue durante dichas temporadas que introdujo a los músicos de esta agrupación a las peculiaridades técnicas de jach'a lakitas. Con los años algunos de sus integrantes viajaron al pueblo de Ilabaya para asistir a las fiestas del Dulce Nombre de Jesús, donde grabaron algunas de las melodías que habrían de usar como material de estudio y fuente de repertorio en Buenos Aires.

Fue hacia 2007 que la actividad musical de Wayramanta se enfocó de modo exclusivo en la interpretación de jach'a lakitas de Ilabaya. En 2013, para conmemorar los veinte años de la fundación del grupo, Wayramanta produjo el que sigue siendo el primer y único disco compacto dedicado en su totalidad a este estilo musical (ver Castelblanco 2015) (ver Figura 5).

Entre los participantes de la escena sikuri de Buenos Aires a quienes pregunté acerca del origen de su interés en el estilo sikuri de Ilabaya, muchos coincidieron en señalar a Wayramanta como la agrupación a la que escucharon interpretarlo por primera vez-en festivales como los de los barrios Charrúa y Villa Celina, en el Mathapi y otras instancias-. De forma significativa, varios apuntaron que -además de las peculiaridades sonoras de la música que interpretabansu singular forma de vestir atrajo su atención, ya que transgredía la etiqueta convencional del vestuario que emplean los intérpretes cosmopolitas de música andina. 


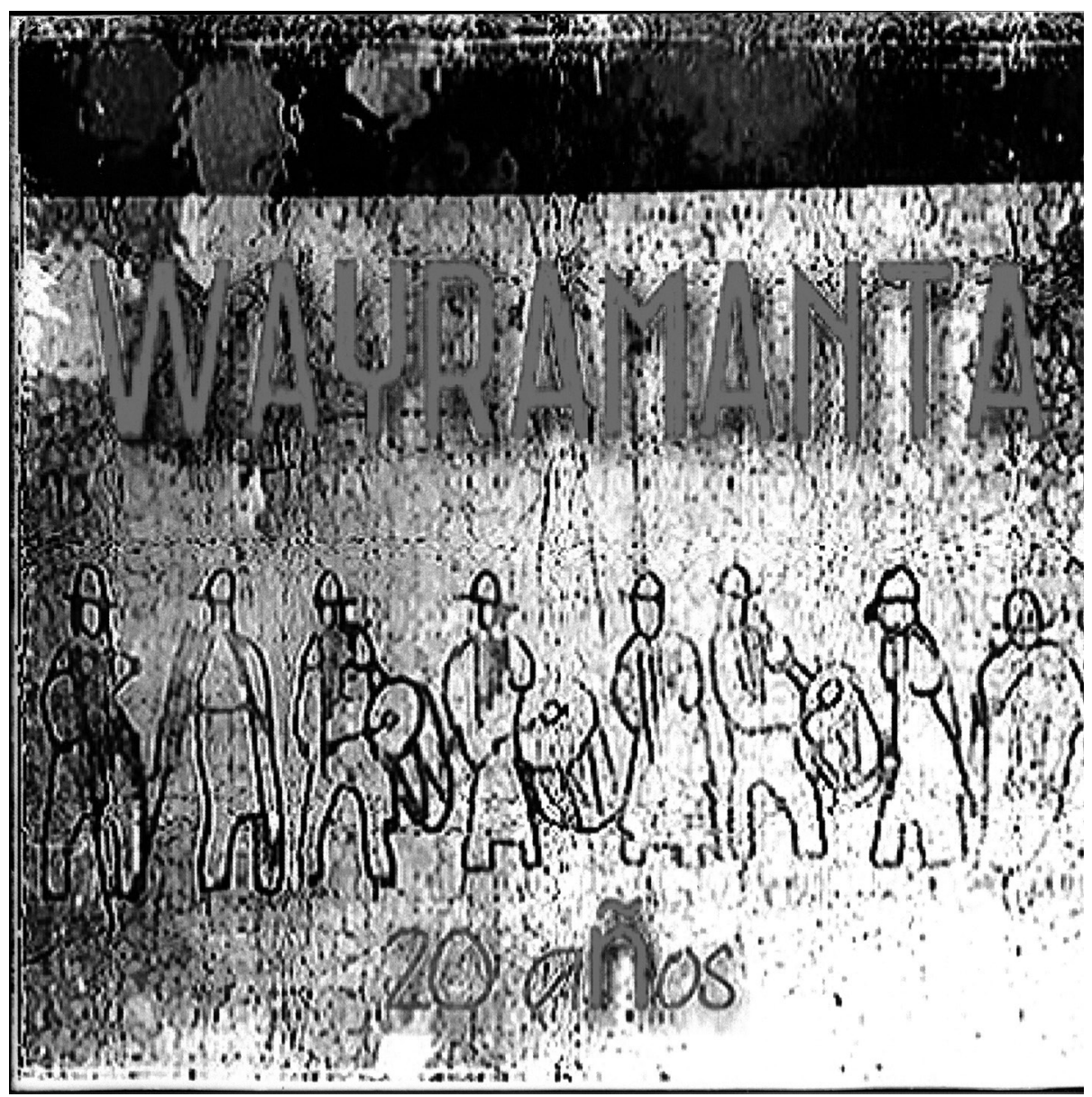

Figura 5: Portada del disco 20 años, por Wayramanta (2013). Fuente: Archivo personal del autor.

En efecto, con los años Wayramanta tomó distancia respecto del atuendo que suele distinguir a las agrupaciones de música andina y que típicamente consta de lluch'u multicolor, poncho a rayas y ojotas. La amplia difusión de esta indumentaria se debe al impacto de larga duración que produjeron las primeras agrupaciones de música andina folclórica-popular que aparecieron ataviadas de modo consistente con dichas prendas -tanto en Europa como en Bolivia-, en las portadas de sus discos, y durante sus escenificaciones de "estampas folclóricas" en peñas, salas de teatro y en la televisión. En su lugar, los músicos Wayramanta privilegian el uso de chaqueta formal, sombrero y, ocasionalmente, la capa blanca y el cortipaño que distingue a los conjuntos de jach'a lakitas que acuden a la plaza de Ilabaya en fechas señaladas. En breve, desde que Wayramanta decidió especializarse en el estilo musical que interpretan los agricultores aymara de esta región andina, ha intensificado sus esfuerzos por replicar con el mayor detalle posible las idiosincrasias sonoras que lo caracterizan. Con ello, la propuesta de Wayramanta desafía las convenciones sonoras y visuales hegemónicas de indigenidad andina que circulan al interior de la cohorte "resurgentista" del movimiento sikuri. 
Es posible atribuir parte del creciente interés en este estilo musical al trabajo de Wayramanta. También puede que aquellas bandas de sikuris argentinos que en años recientes han adoptado una vestimenta semejante a la que emplea Wayramanta, lo hayan hecho por su influencia directa. Incluso es posible que las agrupaciones basadas en esa ciudad que han resuelto especializarse en un estilo musical definido, lo hayan hecho inspirados en la experiencia de Wayramanta.

\subsection{Repertorio canónico de jach'a lakitas}

Pero aquellos conjuntos de sikuris que en años recientes han decidido interpretar jach'a lakitas -desde Valparaíso hasta San Francisco-, enfrentan una dificultad: la escasez de repertorio disponible fuera de las fiestas y otros contextos tradicionales de producción musical. Por este motivo se ha formado algo así como un repertorio canónico de jach'a lakitas basado en las versiones de agrupaciones como Kollamarka, Trencito de los Andes y Willkamayu, principalmente ${ }^{18}$.

En contraste, los conjuntos "resurgentistas" que interpretan kantus de Charazani o "sikuri de Italaque" disponen de un extenso cuerpo discográfico que incluye los vinilos, casetes y compactos producidos por ensambles de diversas comunidades. Del mismo modo, cuentan con grabaciones etnográficas comerciales publicadas desde mediados del siglo pasado por ciertos investigadores, así como con un creciente número de videos de fiestas patronales disponibles en YouTube. Entre tanto, quienes desean interpretar jach'a lakitas dependen de un repertorio limitado de fuentes y, por extensión, de elementos que les permitan conceptualizar aquellas características estéticas que conformarían dicho estilo musical. Como consecuencia, su expansión solo es posible por medio de sus propias grabaciones de campo efectuadas durante fiestas y entradas folklóricas, principalmente.

\section{REFLEXIONES FINALES: UN PROCESO INTRACULTURAL}

Al preguntar a los participantes de diferentes escenas sikuri acerca del origen de su interés en este estilo musical, invariablemente han apuntado a un número limitado de agrupaciones artísticas. Además de Wayramanta, en la ciudad de Buenos Aires, las más recurrentes en esta y otras escenas fueron Willkamayu, Trencito de los Andes y Kollamarka, seguidas de Mojjsa Uma y Comunidad Cultural Wilancha. Este listado es muy elocuente acerca de las condiciones de circulación de este estilo musical y tiene diversas implicaciones.

Salvo en el caso de excepciones notables, la mayoría de las versiones de dichas agrupaciones son adaptaciones simplificadas de la música interpretada por los conjuntos de comunarios durante sus fiestas. Como resultado, en ellas suelen prevalecer los ideales estéticos cosmopolitas por sobre la calidad impredecible y aquellos rasgos que distinguen la producción musical participativa.

Estas versiones procesadas, sin embargo, pueden ser consideradas como pedagógicas en el sentido de que facilitan la comprensión auditiva de músicas que desafían los paradigmas estéticos dominantes y que -en sus contextos tradicionales de interpretación-, a menudo se encuentran imbricadas en un ambiente de saturación sonora que dificulta aún más su

18 El repertorio canónico de jach'a sikuri de Ilabaya incluye "tonos" grabados por Kollamarka como "Jach'a siku" (1984), Trencito de los Andes como "La Parábola de Juvencito" (2000), "Suma Conjunto", "Huaycheña" (2002) y "Jaccha Walata" (2003a), así como versiones de Willkamayu identificadas como "Jach'a laquita" (2002), "Jach'a sicuri", "Jacha laquita", "Kacharpaya" (2004) y "Jach'a lakita" (2016). 
apreciación. Si bien es cierto que las versiones que produjeron agrupaciones artísticas como las mencionadas constituyen la primera vía de acceso a este estilo musical, también lo es que con frecuencia termina siendo la única.

En efecto, la mayoría de los conjuntos de sikuris alineados con la cohorte "resurgentista" fundamenta su trabajo musical en la reinterpretación de las versiones producidas por agrupaciones de música andina folclórica-popular. A lo largo de esta cadena de reinterpretaciones sucesivas ocurren varias modificaciones tanto intencionales como involuntarias. La acumulación progresiva de errores, imprecisiones y correcciones desinformadas hace que, al final de esta cadena, resulten prácticamente indistinguibles aquellas peculiaridades sonoras que precisamente diferencian los jach'a lakitas de otros estilos musicales.

Pero más allá de las distorsiones estéticas inherentes a los procesos de transmisión basados en la oralidad, sostengo que es importante reconocer la condición intracultural de los agentes involucrados en las cadenas de circulación de prácticas y conocimientos que dan forma a la cohorte "resurgentista" y, por extensión, al movimiento sikuri.

En efecto, uno de los aspectos centrales del movimiento sikuri es la celebración de los rasgos culturales de los habitantes indígenas de los Andes. Debido a que los sikuris valoran sus formas alternativas de conocimiento e incluso asumen algunas de sus prácticas musicales y rituales, existe una tendencia generalizada a imaginar el movimiento sikuri como una instancia privilegiada para el intercambio intercultural. En muchos sentidos lo es (Castelblanco 2020: 201-213).

Sin embargo, la formación cultural de los agentes involucrados en la transmisión de los conocimientos y prácticas de los indígenas de los Andes al interior de la cohorte "resurgentista", demuestra que a menudo se trata más bien de intercambios intraculturales. Es decir, que parte importante de las interacciones en este proceso no ocurren a la manera de una dialéctica entre músicos "resurgentistas" y músicos "hechos en casa", sino entre individuos que crecieron inmersos en la misma formación cultural cosmopolita (Gavazzo 2017: 48; Padin 2018: 113; Podhajcer 2015; Turino 2003).

Desde la perspectiva histórica de la música andina esta condición no es excepcional -ni en modo alguno es una característica exclusiva del movimiento sikuri-. Se trata, más bien, de uno de los legados de la Nueva Canción Latinoamericana, cuyo auge en la década de 1970 promovió la apreciación de las músicas indígenas de los Andes a nivel internacional, pero en la que la participación de músicos "hechos en casa" fue prácticamente nula (Ríos 2008). De modo comparable, una parte importante de los conocimientos y prácticas de los indígenas de los Andes circula entre los sikuris por medio de interacciones entre músicos "resurgentistas".

Debido a la ausencia generalizada de intercambios interculturales arraigados en experiencias de intimidad cotidiana, un sector de los participantes del movimiento tan solo cuenta con visiones estereotipadas acerca de los habitantes indígenas de los Andes y sus músicas. De ahí que muchos sikuris repliquen imágenes desterritorializadas y atemporales de los mismos, como la noción de "lo andino" en tanto categoría homogenizante que diluye la profundidad histórica y la diversidad étnica, lingüística y cultural de los pueblos que cohabitan la región ${ }^{19}$.

19 "Lo andino" es un discurso esencialista acerca del "Otro" producido por agentes externos, e impuesta a los habitantes de los Andes para señalar una frontera de orden étnico y cultural. Es un constructo que asume que todos los habitantes de esta región montañosa poseen idénticas inclinaciones culturales, a la vez únicas y coherentes, que incluirían percepciones, entendimientos, valores, símbolos y prácticas. La noción de "lo andino" fue construida por folcloristas, escritores, antropólogos y políticos en la convergencia de sus respectivas agendas investigativas y preocupaciones políticas. Su aparición oficial 
Estas imágenes estáticas suelen estar acompañadas por símbolos generales de indigenidad andina como la wiphala (bandera multicolor ajedrezada que representa a los pueblos indígenas andinos) y la chakana (cruz cuadrada andina), discursos como el del "buen vivir", visiones no problematizadas acerca de instituciones de apoyo mutuo como ayni y minka, y explicaciones celebratorias acerca de estructuras sociales como el chacha-warmi o la dualidad complementaria. Todas estas nociones son fácilmente transferibles y han sido diseminadas con éxito por el Estado boliviano a partir de 2006. El antropólogo británico Andrew Canessa (2016) denomina este tipo de discursos "representaciones mayoritarias hegemónicas de indigenidad" y señala que su propósito es, en efecto, cooptar el Estado.

En contraste, las "representaciones minoritarias contrahegemónicas de indigenidad" están arraigadas en prácticas culturales cotidianas y de carácter íntimo. No son fácilmente compartidas ni transferidas, y pretenden resistir al Estado. Entre los sikuris, solo aquellos que traban relaciones interculturales con músicos "hechos en casa" eventualmente cuestionan el poderoso imaginario hegemónico respecto de "el Otro andino". Pero a pesar de su valor social y cultural, el cultivo de relaciones interculturales no garantiza en modo alguno la comprensión de las convenciones estéticas de los músicos "hechos en casa", ni la destreza en la interpretación de sus instrumentos o estilos musicales.

Además, el interés de los sikuris en los jach'a lakitas eventualmente puede tener un efecto positivo en la percepción que los ilabayeños y demás cultores vernáculos de este estilo regional tienen sobre sus propias prácticas musicales. Así como es posible atribuir parte de la vitalidad que hoy gozan los estilos icónicos de Conima, Charazani y la provincia Camacho al entusiasmo que por ellos expresaron audiencias nacionales e internacionales durante el siglo pasado, es posible que el creciente interés del movimiento sikuri en los jach'a lakitas contribuya a que sus detentores valoren aún más sus propias prácticas musicales y las promuevan con renovados bríos.

\section{BIBLIOGRAFÍA}

ACEvedo, SAÚl

2003 Los sikuris de San Marcos: historia del Conjunto de Zampoñas de San Marcos. Lima: Alter-Nativa.

Albó, Xavier

1991 "El retorno del indio", Revista Andina, IX/2, pp. 299-366.

Barragán, Fernando, y Pablo Mardones

2018 "Marcar las diferencias: construcciones sonoro-estilísticas de las bandas de sikuris de Buenos Aires", Música y sonidos en el Mundo Andino: flautas de pan, zampoñas, antaras, sikus y ayarachis. Carlos Sánchez (editor). Lima: Universidad Nacional Mayor de San Marcos, pp. 535-554.

se produjo en el segundo volumen del Handbook of South American Indians (1946), una obra enmarcada dentro de la corriente de los estudios de "área cultural" cuya finalidad consistía en conceptualizar la relación entre territorio y cultura como entidades totales (De la Cadena 1990: 67; Poole 1992: 212). El propósito comparativo que caracterizó el empleo inicial del concepto se diluyó con el paso de los años. $\mathrm{Al}$ mismo tiempo, un sector de la academia con antecedentes indigenistas promovió la ideologización de la noción de "lo andino" y definió algunos de sus atributos, como la dualidad y la reciprocidad, como si fuesen rasgos culturales específicamente andinos (De la Cadena 1990: 67-68). Más aún, definió "lo andino" por oposición a la formación cultural cosmopolita hegemónica (i.e., capitalista, cristiana y modernista) (Poole 1992: 216). Como consecuencia, distintos segmentos sociales percibieron "lo andino" como algo que debía ser destruido, superado, asimilado, valorado, celebrado, transformado o rescatado dependiendo de sus respectivos programas políticos y económicos (Van Dam y Salman 2003). 
Baumann, Max Peter

1982 "Music in the Andean Highlands", Bolivien: Musik im Andenhochland [LP]. Max Peter Baumann (editor). Berlín: Museum für Völkerkunde, pp. 25-39.

Bedregal de Conitzer, Yolanda y Antonio González Bravo

1956 Calendario folklórico del departamento de La Paz: con un pequeño glosario de música y danzas indígenas. La Paz: Municipalidad de La Paz.

Bigenho, Michelle

2002 Sounding Indigenous: Authenticity in Bolivian Music Performance. Nueva York: Palgrave McMillan. DOI: $10.1007 / 978-1-137-11813-4$

2012 Intimate Distance: Andean Music in Japan. Durham, NC: Duke University Press. DOI: $10.1215 / 9780822395317$

Canessa, Andrew

2016 "Paradoxes of Multiculturalism in Bolivia". Congreso Internacional de la Asociación de Estudios Latinoamericanos (LASA), Nueva York. Mayo. Ponencia.

Castelblanco, Daniel

2015 "Wayramanta: 20 años. Jacha laquitas. La Paz, Bolivia”, Critical Reviews on Latin American Research, IV/2 (otoño-invierno), pp. 66-69.

2017 "Dos intelectuales indigenistas y su influencia en la popularización del estilo musical de los sikuris de Italaque (1926-1963)”, Revista Mundo Sikuri, 2, pp. 32-38.

2018 "Sikuris altiplánicos, regionales y metropolitanos: revisión de un esquema de clasificación", Música y sonidos en el Mundo Andino: flautas de pan, zampoñas, antaras, sikus y ayarachis. Carlos Sánchez (editor). Lima: Universidad Nacional Mayor de San Marcos, pp. 485-510.

2019 "Del ayllu a la metrópoli: transformación de los usos y significados de la música aymara al interior de una comunidad transnacional de resurgentistas de la música andina”, Latin American Music Review, XL/2 (otoño-invierno), pp. 105-137. DOI: 10.7560/LAMR40201

2020 “No somos nadie sin el otro»: autenticidad y ciudadanía al interior de una comunidad transnacional de «resurgentistas» de la música andina”, Anthropologica, XXXVIII/45, pp. 187218. DOI: $10.18800 /$ anthropologica.202002.008

Céspedes, Gilka Wara

1984 "New Currents in "Música Folklórica" in La Paz, Bolivia", Latin American Music Review, V/2 (otoño-invierno), pp. 217-242.

De la Cadena, Marisol

1990 "De utopías y contrahegemonías: el proceso de la cultura popular", Revista andina, 15, pp. 65-76.

FALcón, José

2007 "Los sikuris de Lima: una historia inconclusa", Todo siku/ri: estudios en torno al siku y al sikuri. Saúl Acevedo (editor). Lima: Centro Cultural de la Universidad Nacional Mayor de San Marcos, pp. 107-120.

Gavazzo, Natalia

2017 "Sikuris en Buenos Aires: la música como herramienta de participación de los migrantes bolivianos y sus hijos”, Ceremoniales festivos: Argentina, Bolivia, Brasil, Colombia y México. Marcos González (editor). Bogotá: Intercultura Colombia, pp. 37-54.

González, JuAn Pablo

2012 "Música chilena andina 1970-1975: construcción de una identidad doblemente desplazada", Cuadernos de música iberoamericana, 24, pp. 175-186. DOI: 10.5209/CMIB

GonzÁlez Bravo, Antonio

1936 “Sicus”, Boletín Latino Americano de Música, 2, pp. 253-257. 
1949 "Música, instrumentos y danzas indígenas", La Paz en su IV centenario: 1548-1948. Comité Pro IV centenario de la fundación de La Paz (editor). Tomo III. La Paz: Comité Pro IV centenario de la fundación de La Paz, pp. 403-423.

HOLT, FABIAN

2007 Genre in Popular Music. Chicago: The University of Chicago Press.

Katz-Rosene, JoshuA

2015 "Discourse in Música Latinoamericana Cultural Projects: From Nueva Canción to Colombian Canción Social”, Volume! XI/2, pp. 65-83. DOI: 10.4000/volume.4500

LiVINGSTON, TAMARA

2014 "An Expanded Theory for Revivals as Cosmopolitan Participatory Music Making”, The Oxford Handbook of Music Revival. Caroline Bithell y Juniper Hill (editoras). Oxford: Oxford University Press, pp. 60-69. DOI: 10.1093/oxfordhb/9780199765034.013.018

Mendívil, Julio y Christian Spencer

2016 "Epilogue: Reconsidering Music Scenes from a Latin American Perspective", Made in Latin America. Julio Mendívil y Christian Spencer (eds.). Nueva York: Routledge, pp. 160-164. DOI: $10.4324 / 9781315880549$

Mora, Gerardo (EDitor)

2012 Lakitas en Arica: zampoñas, sopladores y ritmos en el Norte de Chile. Santiago: Azapa producciones.

PAdin, Esteban

2018 "La comunidad como forma de integración y organización de los sicuris en Buenos Aires", Anthropologica, 40, pp. 121-141. DOI: 10.18800/anthropologica.201801.006

Pedro, Josep, Ruth Piquer y Fernán del Val

2018 "Repensar las escenas musicales contemporáneas: genealogía, límites y aperturas", Cuadernos de Etnomusicología, 12, pp. 63-88.

Peterson, Richard y Andy Bennett

2004 "Introducing Music Scenes". Music Scenes: Local, Translocal, and Virtual. Andy Bennett y Richard Peterson (editores). Nashville, TN: Vanderbilt University Press, pp. 1-15.

Podhajcer, Adil

2015 "Sembrando un cuerpo nuevo. Performance e interconexión en prácticas musicales «andinas» de Buenos Aires”, Revista Musical Chilena, LXIX/223, pp. 47-65. DOI: 10.4067/ s0716-27902015000100004

PoOle, Deborah

1992 "Antropología e historia andinas en los EE.UU: buscando un reencuentro", Revista Andina, X/1, pp. 209-245.

Ríos, FERnANDo

2008 "La Flûte Indienne: The Early History of Andean Popular-Folkloric Music in France and its Impact on Nueva Canción”, Latin American Music Review, XXIX/2 (otoño-invierno), pp. 145-181.

2005 "Music in Urban La Paz, Bolivian Nationalism and the Early History of Cosmopolitan Andean Music: 1936-1970”. Tesis doctoral. University of Illinois at Urbana-Champaign.

SÁNCHez, CARlos

2013 La flauta de pan andina: los grupos de sikuris metropolitanos. Estudio sobre los conjuntos de zampoñas, sikuris limeños, urbanos o metropolitanos. Lima: Universidad Nacional Mayor de San Marcos.

2016 "El proyecto 'Vientos de Lima: Zampoñas urbanas' y los sikuris urbanos, limeños o metropolitanos", Vientos de Lima: hamuqkuna [CD]. Zampoñas Urbanas (editor). Lima: Zampoñas Urbanas, pp. s.n.

TARRILlo, DANY

1998 "El CZSM y el estilo Ilave", Kachkaniraqkun, 7, pp. 20. 
Turino, THOMAS

1993 Moving Away from Silence: Music of the Peruvian Altiplano and the Experience of Urban Migration. Chicago: University of Chicago Press.

2003 "Are We Global Yet? Globalist Discourse, Cultural Formations and the Study of Zimbabwean Popular Music”, British Journal of Ethnomusicology, XII/2, pp. 51-79.

2008 Music as Social Life: The Politics of Participation. Chicago: University of Chicago Press.

2018 "Participatory Performance and the Authenticity of Place in Old-time Music", The Routledge Companion to the Study of Local Musicking. Suzel Reily y Katherine Brucher (editoras). Nueva York: Routledge, pp. 17-28. DOI: 10.4324/9781315687353-3

VALENCIA, AmÉrico

1983 El siku bipolar altiplánico: estudio, método y proyección del siku o zampoña altiplánica. Recopilación y aspectos de la música del Altiplano. vol. 1. Los sikuris y pusamorenos. Lima: Artex.

VAN DAm, Anke y Ton SAlman

2003 "Andean Transversality: Identity between Fixation and Flow", Imaging the Andes: Shifting Margins of a Marginal World. Annelies Zoomers y Ton Salman (editores). Amsterdam: Aksant, pp. 15-39.

Vega, María Alejandra

2016 "Rebuilding the Pre-hispanic Religiosity in an Urban Area: the Case of the Urban Sikus Bands in Buenos Aires", Sociology and Anthropology, XII/4, 1066-1078. DOI: 10.13189/sa.2016.041205

VIDAL, CARLOS

2012 "Sikuri: tradición o cambio", Revista Mundo Sikuri, 1, pp. 8-10.

Wahren, Cecilia

2016 Encarnaciones de lo autóctono: prácticas y políticas culturales en torno a la indianidad en Bolivia a comienzos del siglo XX. Buenos Aires: Teseo.

\section{DISCOGRAFÍA}

Bolivia Manta

1989 Tikuna $[\mathrm{CD}]$. Francia: ASPIC.

Conjunto Yacachi Chico

c.a. 1970 Música del conjunto Yacachi Chico (Prov. Omasuyos) [EP]. Bolivia: Wayra.

Grupo AyMARA

1976 Concierto en los Andes de Bolivia [LP]. Bolivia: Lauro.

1982 Grupo Aymara [LP]. Bolivia: Lyra.

1995 Soul of Aymara [CD].Japón: Seven Seas.

Grupo Phaxi Qhana

1999 Festive Music of the Andes [CD]. Japón: JVC.

KOLLAMARKA

1984 Kollamarka [LP]. Bolivia: Lyra.

1994 Lo mejor [CD]. Bolivia: Discolandia.

2002 De tierra adentro. Horak'e mankharu [CD]. Bolivia: Maná Records.

Kollasuyu Nan Bolivia

1986 Jallpataqui: Feast of the Earth [LP]. Bélgica: Kollasuyu Nan Bolivia.

LOS RUPHAY

1981 Kollasuyo: Bolivia [LP]. Bolivia: Heriba. 
Osvaldo Torres y Conjunto Huara

1980 Desde los Andes a la ciudad [Casete]. Chile: Alerce.

Trencito de los Andes

1990 Jaccha sikuris [Casete no comercial].

2000 Escarcha y sol [CD]. Italia: Malqui.

2002 Il puma e gli arconauti [CD]. Italia: Hierofantes Producciones / Malqui.

2003a Continente líquido 1: Castellino delle Formiche 1989/91 [CD]. Italia: Hierofantes Producciones.

2003b Continente líquido 3: Castellino delle Formiche 1989/91 [CD]. Italia: Hierofantes Producciones.

2006 Opus primum: Sicv Phvsiris. Jjaqtassiña Irampi Arcampi [CD]. Italia: Hierofantes Producciones.

WAYRAMANTA

2005 Música tradicional andina: 12 años [CD]. Argentina: Wayramanta.

201320 años. Jacha laquitas: La Paz - Bolivia [CD]. Argentina: Wayramanta.

WiLlKamayu

2002 Wayna tambo [CD]. Bolivia: Wayna Tambo.

2004 Achachilanakaru [CD]. Bolivia: Wayna Tambo.

2016 Pachamama Nusta [CD]. Bolivia: Wayna Tambo. 